\title{
Glycated haemoglobin (HbA1c) use and glycaemic control in patients living with diabetes mellitus attending public healthcare facilities in KwaZulu-Natal Province, South Africa
}

\author{
S Pillay, ${ }^{1}$ PhD, FCP (SA), MMed (Int Med), MB ChB; D Pillay, ${ }^{2}$ 1st-year medical student; R Pillay, ${ }^{3}$ Grade 10 scholar \\ ${ }^{1}$ King Edward VIII Hospital, and Department of Internal Medicine, Nelson R Mandela School of Clinical Medicine, University of KwaZulu-Natal, \\ Durban, South Africa \\ ${ }^{2}$ Faculty of Health Sciences, University of the Free State, Bloemfontein, South Africa \\ ${ }^{3}$ Clifton College, Durban, South Africa
}

Corresponding author: S Pillay (drspillay@iafrica.com)

\begin{abstract}
Background. Ideal control of diabetes mellitus (DM) remains a global goal, which has not yet been reached. As part of an integrated public healthcare strategy, data with subsequent analysis of diabetes control achieved in patients living with DM (PLWD) need to be available. Diabetes control data from KwaZulu-Natal (KZN) Province, South Africa, are scarce. Smaller studies conducted in public and private healthcare sectors of KZN have shown suboptimal DM control.

Objectives. To identify the percentage of glycated haemoglobin (HbAlc) tests done in KZN public healthcare facilities, and to provide a glimpse into diabetes control being achieved in each KZN district municipality.

Methods. Data regarding the number of HbAlc tests performed, number of patients with an $\mathrm{HbAlc} \leq 7 \%$ and number of diabetes visits were accessed from the KZN Department of Health Information Systems and analysed.

Results. The majority of $\mathrm{HbAlc}$ tests were performed in the metro municipality of eThekwini $(p<0.001)$. Approximately two-thirds $(64.5 \%)$ of PLWD in whom HbA1c tests had been performed, were suboptimally controlled. In 5 of the $11 \mathrm{KZN}$ district municipalities more than two-thirds of PLWD had an HbAlc $>7 \%$. Most of the patients in 9 of the 11 district municipalities showed suboptimal control of their DM. The total number of HbAlc tests performed in KZN represents approximately one-tenth of the total number of diabetes treatment visits. This trend was prevalent in all 11 district municipalities, where the incidence of DM was on an upward trajectory.

Conclusions. Our study demonstrated that the majority of PLWD visiting public healthcare facilities in KZN have suboptimal glycaemic control. They are at increased risk of developing diabetes-related complications, further burdening the healthcare fiscus of low- to middleincome countries. We also showed that the number of HbAlc tests being performed, in the presence of suboptimal control, was well below par. This finding serves to emphasise the need for strategies to be implemented to increase awareness of HbAlc testing for the monitoring of glycaemic control, and for making point-of-care HbAlc testing readily available in these healthcare facilities.
\end{abstract}

S Afr Med J 2021;111(11):1060-1064. https://doi.org/10.7196/SAMJ.2021.v111111.15925

Ideal control of diabetes mellitus (DM) remains a global goal, which has not been achieved in developed and developing countries. ${ }^{[1,2]}$ As part of an integrated public healthcare strategy, data need to be available on current diabetes control achieved in patients living with DM (PLWD). Data on diabetes control in KwaZulu-Natal (KZN) Province, South Africa (SA), are scarce. Smaller studies conducted in both public and private healthcare sectors of KZN have shown that control of DM remains suboptimal. ${ }^{[3-5]}$

Glycated haemoglobin (HbAlc) testing is used for the diagnosis and monitoring of DM. This test provides an average of the patient's blood sugar levels over the preceding 3 months. The current diabetes guidelines of the Society for Endocrinology, Metabolism and Diabetes of South Africa (SEMDSA) suggest that HbAlc testing should be performed at a minimum of 6 - 12-monthly intervals, depending on diabetes control achieved in PLWD. The 2017 SEMDSA guidelines also mention the use of HbA1c testing for the diagnosis of DM, making particular reference to the need for two $\mathrm{HbAlc}$ tests to be performed at least 3 months apart. SA, and other countries globally, define an $\mathrm{HbAlc}$ value for optimal diabetes control as $<7 \%$, except in specific circumstances, such as in the elderly, where the target HbAlc might range between $7 \%$ and $8 \% .{ }^{[6]}$ Poor diabetes control has been shown to increase the risk of developing diabetes-related complications. ${ }^{[7]}$ Currently, a formal venous blood sample is drawn and sent to the laboratory for $\mathrm{HbAcl}$ testing. The HbAlc result is often reviewed months later in a busy healthcare facility. This system is far from optimal if our goal is to improve diabetes control and thereby decrease the development of complications of the disease.

The KZN Department of Health Information Systems (DHIS) has been collecting data from PLWD who attend public healthcare facilities that use data elements. These elements do not include the number of $\mathrm{HbAlc}$ tests being done and do not indicate the current state of diabetes control achieved in the KZN diabetes population. In 2020, two new data elements were added to the existing elements being collected, i.e. the number of patients who had HbAlc tests done and the number of diabetes patients with an $\mathrm{HbAlc} \leq 7 \%$.

The ideal scenario would entail uploading the individual $\mathrm{HbAlc}$ results and geographical location wirelessly for the Department of Health to assess the actual control being achieved by patients in each 
district and metro municipality. Point-of-care HbAlc devices will aid this process, as these will provide results in 3 - 5 minutes and will also wirelessly upload the result and geographical location to the DHIS database for analysis.

This study assisted in identifying the percentage of HbAlc tests done in KZN public healthcare facilities and provides a glimpse into diabetes control achieved in each district municipality of KZN.

\section{Methods}

This was a quantitative, observational, descriptive retrospective study. $\mathrm{KZN}$ is the second most populated province of SA and comprises 10 districts and 1 metro municipality. The DHIS receives data from all healthcare facilities in KZN and aggregates these data per district municipality. In 2020, two new data elements were added for collection per facility:

- diabetes client with $\mathrm{HbA1c} \leq 7 \%$

- diabetes client with HbAlc test conducted.

Permission was requested from the DHIS to access these data. Approval was sought from the DHIS for diabetes-related data elements collected from 1 April 2020 to 31 March 2021. The data elements for each district municipality in KZN that were collected from the DHIS included:

- diabetes client with HbA1c $\leq 7 \%$

- diabetes client with HbAlc test conducted

- diabetes treatment visits.

Once approval had been received from the University of KwaZuluNatal Biomedical Research Ethics Committee (ref. no. BREC 2883/2021) and the Department of Health, these data were accessed and analysed to determine the number of:

- HbAlc tests being done in PLWD in each district municipality of KZN

- $\mathrm{HbAlc}$ results that were $\leq 7 \%$

- HbA1c results that were $>7 \%$

- diabetes visits in each district municipality of KZN

- percentage of $\mathrm{HbAlc}$ tests done annually per district (total number of tests done/diabetic visits $\times 100$ ).

Optimal glycaemic control was defined as an $\mathrm{HbAlc} \leq 7 \%$ as per SA diabetes guidelines. ${ }^{[6]}$

\section{Data collection and statistical analysis}

Simple descriptive statistics were used to describe the sample groups. A $p$-value $<0.05$ was regarded as statistically significant.

\section{Results}

Table 1 demonstrates that the significant majority of $\mathrm{HbAlc}$ tests were performed in the metro municipality of eThekwini $(p<0.001)$. Approximately two-thirds (64.5\%) of PLWD in whom HbAlc tests had been performed were suboptimally controlled. In 5 of the 11 district municipalities more than two-thirds of PLWD had an HbAlc $>7 \%$, which included a metro municipality.

Fig. 1 shows that the majority of HbAlc tests performed in the district municipalities of KZN produced results reflecting suboptimal control.

Figs 2 and 3 demonstrate that the majority of patients in 9 of the 11 district municipalities showed suboptimal control of their DM.

The majority of PLWD in all district municipalities had suboptimal glycaemic control throughout the 12-month study period. Of note is that PLWD from the district of uThukela performed much better than those from other KZN districts with regard to glycaemic control (Fig. 4).

There were significant differences $(p<0.05)$ in 5 of the 11 district municipalities in terms of the percentage of patients who had optimal v. suboptimal control (Table 2).

The total number of $\mathrm{HbA1c}$ tests performed in KZN represented approximately one-tenth of the total number of diabetes treatment visits. This trend was prevalent in all 11 district municipalities (Table 3).

The incidence rate for diabetes in KZN showed an upward trajectory, which was true for all district municipalities (Fig. 5).

\section{Discussion}

Optimal diabetes control remains the epitome of global treatment goals in an attempt to decrease diabetes-related micro- and macrovascular complications. ${ }^{[7]} \mathrm{HbAlc}$ testing provides a method of monitoring long-term glycaemic control. The current SEMDSA guidelines advocate the use of HbAlc testing at 3-6-monthly intervals, depending on glycaemic control being achieved in PLWD. ${ }^{[6]}$ The problem encountered in KZN, the second most populated province of $\mathrm{SA}$, is that scarce data are collected via the DHIS on control achieved by PLWD and the number of HbAlc tests

Table 1. HbAlc tests performed and control achieved per district municipality

\begin{tabular}{|c|c|c|c|c|c|}
\hline $\begin{array}{l}\text { District } \\
\text { municipalities }\end{array}$ & $\begin{array}{l}\text { HbA1c tests } \\
\text { performed on } \\
\text { known PLWD, } \\
n(\%)\end{array}$ & $\begin{array}{l}\text { HbAlc } \leq 7 \%, \\
n(\%)\end{array}$ & $\begin{array}{l}\text { HbAlc }>7 \%, \\
n(\%)\end{array}$ & $\begin{array}{l}\text { PLWD } \\
\text { controlled, \% }\end{array}$ & $\begin{array}{l}\text { PLWD } \\
\text { suboptimally } \\
\text { controlled, \% }\end{array}$ \\
\hline Amajuba & $2244(3.36)$ & $1136(4.79)$ & $1108(2.57)$ & 50.62 & 49.38 \\
\hline eThekwini & $26389(39.51)$ & $7701(32.47)$ & $18688(43.38)$ & 29.18 & 70.82 \\
\hline Harry Gwala & $2239(3.35)$ & $454(1.91)$ & $1785(4.14)$ & 20.28 & 79.72 \\
\hline iLembe & $5492(8.22)$ & $1911(8.06)$ & $3581(8.31)$ & 34.80 & 65.20 \\
\hline King Cetshwayo & $4579(6.86)$ & $2003(8.45)$ & $2576(5.98)$ & 43.74 & 56.26 \\
\hline Ugu & 4939 (7.39) & $1605(6.77)$ & 3334 (7.74) & 32.50 & 67.50 \\
\hline uMgungundlovu & $8119(12.15)$ & $3340(14.08)$ & 4779 (11.09) & 41.14 & 58.86 \\
\hline uMkhanyakude & $2583(3.87)$ & $1273(5.37)$ & $1310(3.04)$ & 49.28 & 50.72 \\
\hline uMzinyathi & 2635 (3.94) & $1102(4.65)$ & $1533(3.56)$ & 41.83 & 58.18 \\
\hline uThukela & $2145(3.21)$ & $1278(5.39)$ & $867(2.01)$ & 59.58 & 40.42 \\
\hline Zululand & $5433(8.13)$ & $1912(8.06)$ & $3521(8.17)$ & 35.19 & 64.81 \\
\hline Total & 66797 & 23715 & 43082 & 35.51 & 64.50 \\
\hline
\end{tabular}




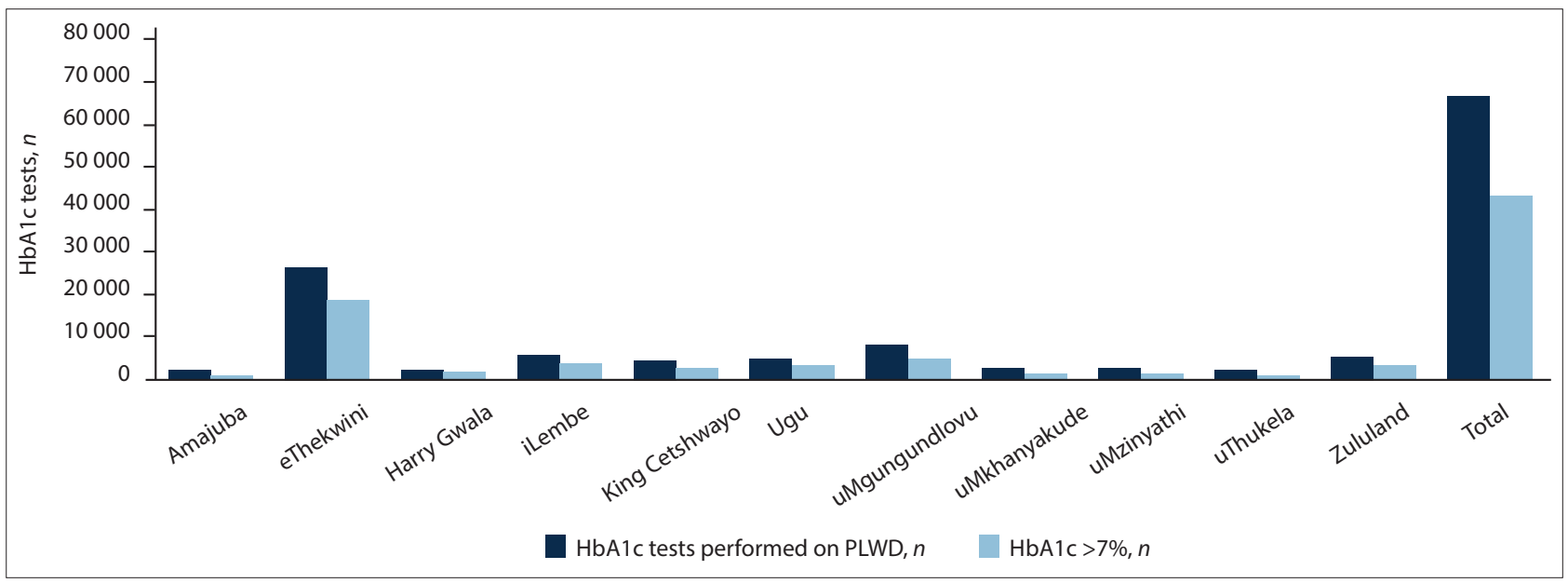

Fig. 1. HbA1c tests (n) performed v. suboptimal control. (HbA1c=glycated haemoglobin; PLWD = patients living with diabetes mellitus.)

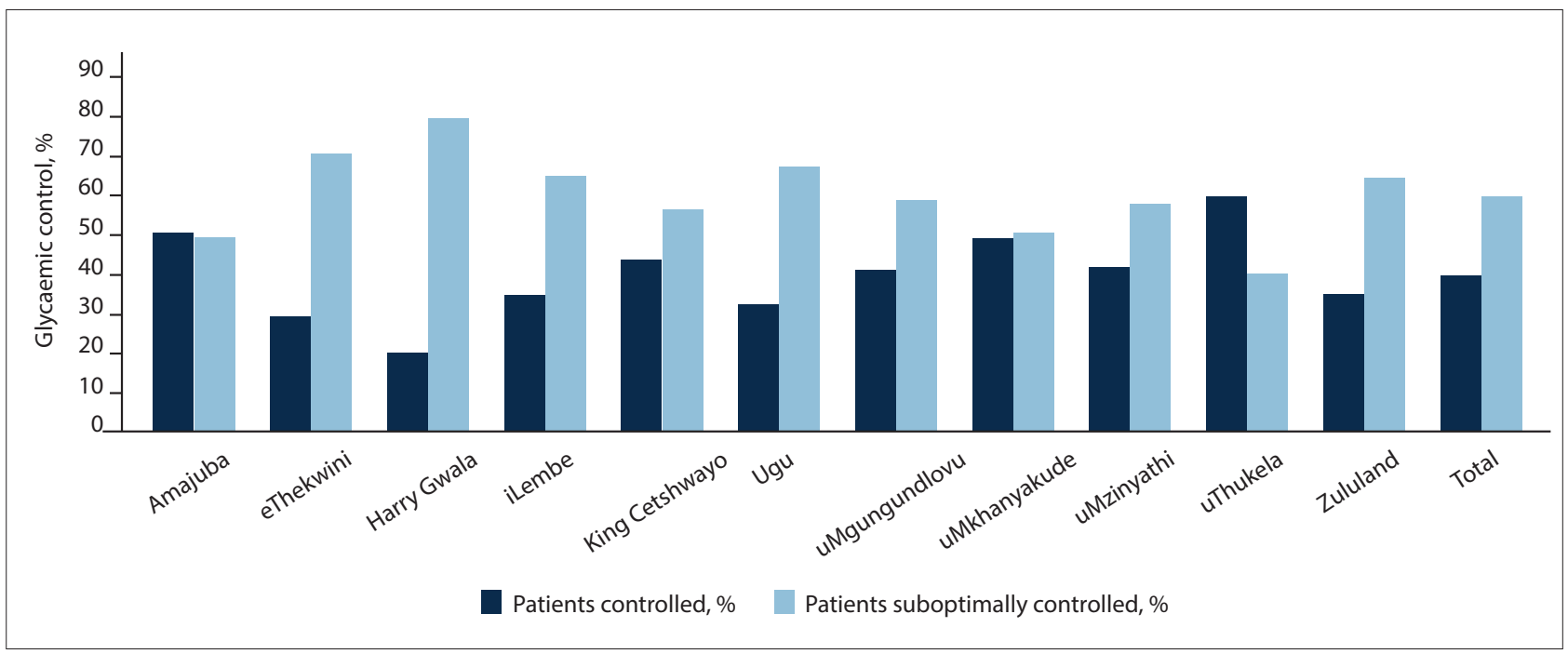

Fig. 2. Optimal v. suboptimal glycaemic control.

\begin{tabular}{|c|c|c|c|}
\hline District municipalities & PLWD controlled, $\%$ & PLWD suboptimally controlled, \% & $p$-value \\
\hline Amajuba & 50.62 & 49.38 & 0.9 \\
\hline eThekwini & 29.18 & 70.82 & $<0.01$ \\
\hline Harry Gwala & 20.28 & 79.72 & $<0.01$ \\
\hline iLembe & 34.8 & 65.20 & 0.002 \\
\hline King Cetshwayo & 43.74 & 56.26 & 0.21 \\
\hline Ugu & 32.5 & 67.50 & $<0.01$ \\
\hline uMgungundlovu & 41.14 & 58.86 & 0.08 \\
\hline uMkhanyakude & 49.28 & 50.72 & 0.89 \\
\hline uMzinyathi & 41.82 & 58.18 & 0.10 \\
\hline uThukela & 59.58 & 40.42 & 0.06 \\
\hline Zululand & 35.19 & 64.81 & $<0.01$ \\
\hline Average & - & 60.17 & - \\
\hline
\end{tabular}

being performed. Smaller studies, however, completed in both the public and private sectors in KZN, have demonstrated suboptimal diabetes control. ${ }^{[3-5]}$

Our study revealed that the bulk of HbAlc testing was being performed in eThekwini and uMgungundlovu - KZN district municipalities that have the highest recorded populations and that are the most urbanised. We postulate that HbAlc tests are being performed with greater frequency in urban areas, as these samples are more easily transported to on- and off-site laboratories for testing, with shortened turnaround times for reporting of results. In contrast, more remotely situated and rural-based healthcare facilities often have to send samples to an off-site facility, resulting in a delay 
of result reporting. This creates a scenario where HbAlc tests are only performed if and when PLWD present with complications or are hospitalised. Another possibility for these findings rests in access to continuing professional development (CPD) for

\begin{tabular}{lll}
\multicolumn{3}{l}{ Table 3. HbA1c tests performed as a percentage of total number of PLWD visits } \\
\hline District municipalities & $\begin{array}{l}\text { HbA1c tests performed } \\
\text { on PLWD, } \boldsymbol{n}\end{array}$ & $\begin{array}{l}\text { Diabetes treatment } \\
\text { visits, } \boldsymbol{N}(\%)\end{array}$ \\
\hline Amajuba & 2244 & $33203(6.76)$ \\
eThekwini & 26389 & $297166(8.89)$ \\
Harry Gwala & 2239 & $38888(5.76)$ \\
iLembe & 5492 & $46482(11.82)$ \\
King Cetshwayo & 4579 & $82461(5.55)$ \\
Ugu & 4939 & $70370(7.02)$ \\
uMgungundlovu & 8119 & $96646(8.40)$ \\
uMkhanyakude & 2583 & $40626(6.36)$ \\
uMzinyathi & 2635 & $39712(6.64)$ \\
uThukela & 2145 & $57091(3.76)$ \\
Zululand & 5433 & $58630(9.27)$ \\
Total & 66797 & $861275(7.76)$ \\
HbAlc = glycated haemoglobin; PLWD $=$ patients living with diabetes mellitus.
\end{tabular}

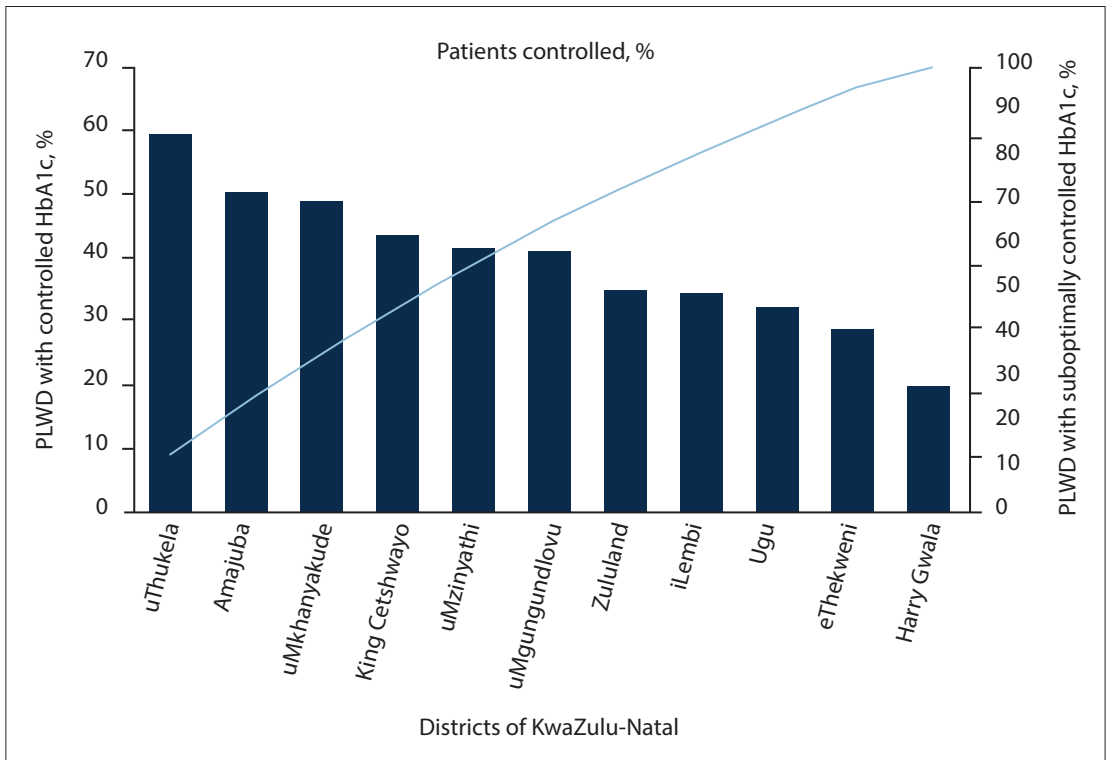

Fig. 3. Pareto graph, demonstrating glycaemic control in district municipalities. (PLWD $=$ patients living with diabetes mellitus; HbAlc = glycated haemoglobin.)

clinicians who order the HbAlc tests and manage diabetes control. Urban clinicians have easier access to CPD activities, allowing them to keep abreast of medical guidelines, including those for DM. During the COVID19 pandemic, information dissemination has become more encompassing and many, if not all, CPD activities are presented via internetbased media. These circumstances serve to broaden the reach of these activities. Internet connectivity is a drawback in low- to-middleincome countries (LMIC), such as SA, which might hamper the process. More information needs to be disseminated to clinicians working in all districts of KZN, covering all aspects of diabetes care, especially on the use of $\mathrm{HbAlc}$ testing in managing and improving diabetes control. Point-of-care HbAlc testing might provide a solution for rural healthcare facilities, as it provides results in $3-5$ minutes, allowing clinicians to make therapeutic and lifestyle decisions at the index clinic visit.

Of the PLWD who underwent HbAlc tests, two-thirds had $\mathrm{HbAlc}$ values $>7 \%$, indicating suboptimal control. In 5 of the 11 district municipalities (45.45\%), more than two-thirds of PLWD had suboptimal glycaemic control. Overall, in 9 of the 11 district municipalities, there were $>50 \%$ of PLWD with suboptimal glycaemic control. Pillay et al. ${ }^{[3]}$ used diabetes-related amputations in KZN as a surrogate marker of glycaemic control, alluding to the poor control achieved by PLWD residing in KZN. Our study provides concrete evidence that there is widespread poor glycaemic control in KZN. PLWD from the eThekwini and uMgungundlovu district municipalities had the greatest number of suboptimal HbAlc results. These results concur with those of studies showing that urbanised populations have poorer glycaemic control than rural populations. ${ }^{[8]}$

The total number of $\mathrm{HbAl}$ c tests performed during this 1-year study represented only

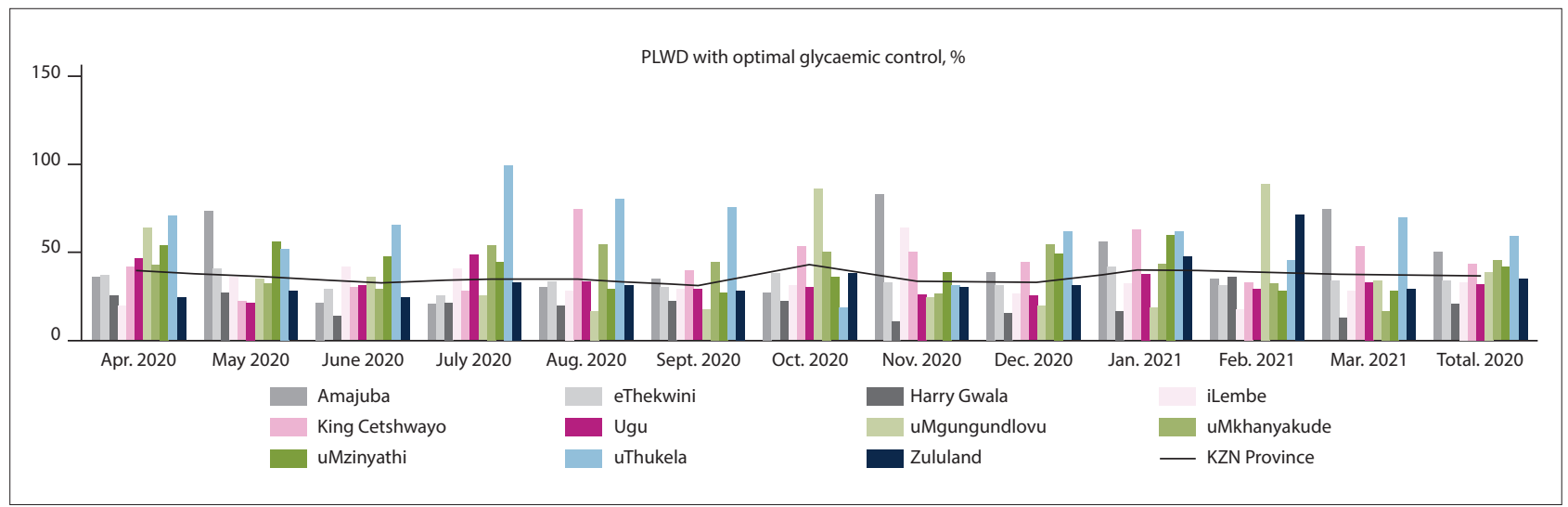

Fig. 4. PLWD (\%) achieving optimal glycaemic control (monthly) per district municipality. (PLWD = patients living with diabetes mellitus; KZN = KwaZulu-Natal.) 


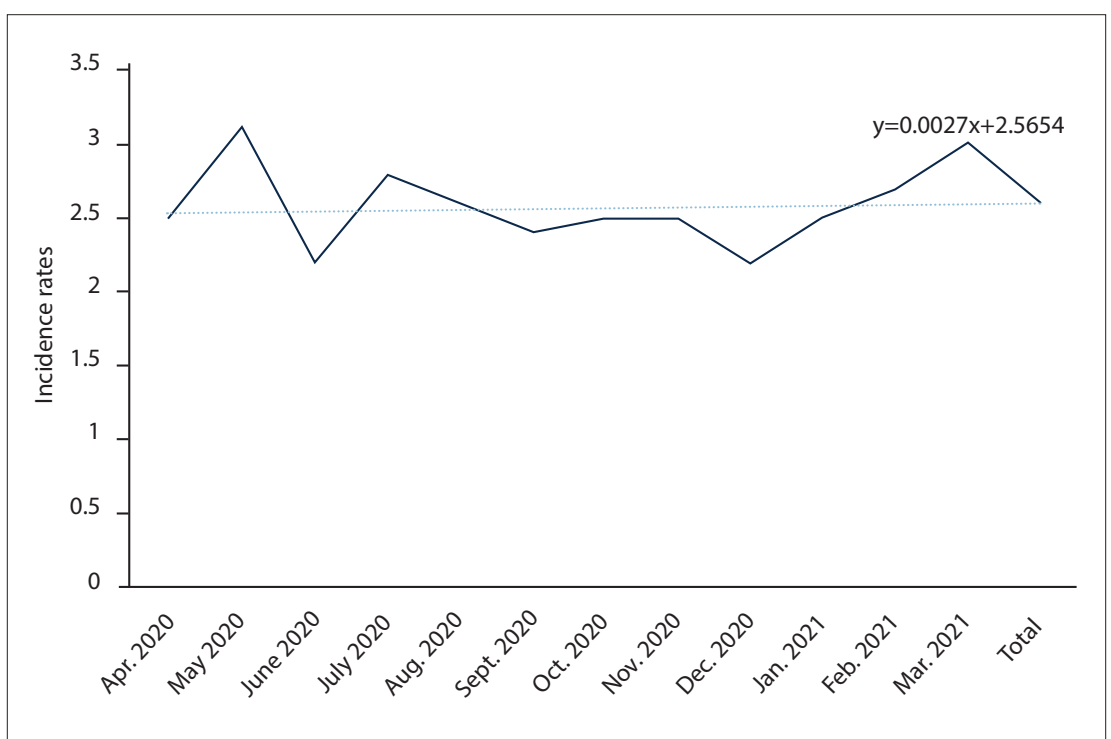

Fig. 5. Monthly diabetes incidence rates in KwaZulu-Natal.

$7.76 \%$ of the total number of diabetes visits (range 3 - 12\%). This trend was found in both metro and district municipalities. The SEMDSA guidelines suggest performing HbAlc tests every 3 - 6 months, depending on the level of glycaemic control. ${ }^{[6]}$ We demonstrated that in most of the district municipalities, there was a significant majority of PLWD with suboptimal control. Taking this poor glycaemic control into account, coupled with the current SEMDSA diabetes guidelines, there should have been many more HbAlc tests performed during the study period. Studies have shown that regular monitoring of HbAlc in PLWD leads to improved glycaemic control, which in turn translates into decreased diabetes complications. ${ }^{[7,9]}$ These findings must alert the Department of Health to implement strategies to increase HbAlc testing. One such approach is to improve the training of clinicians and nurses working in KZN regarding diabetes care and control. Larger audiences can now be attained with the escalated use of internetbased media for educational purposes. A second recommendation is the increased use of point-of-care $\mathrm{HbAlc}$ testing devices in these facilities as part of ascertaining vital clinical signs, such as blood pressure measurement and urine dipstick readings. These measures ensure that the attending clinician has the HbAlc test at the time of consultation, allowing him/her to make therapeutic and lifestyle decisions. The pointof-care HbAlc testing devices also have the ability to wirelessly upload their results, together with the geographical location, to a central database controlled by DHIS. Analysis of these results on a daily/weekly/ monthly basis will allow the Department of Health to identify poorly performing district municipalities and implement strategies to improve control in these areas. It will also enable the Department of Health to audit whether these interventions have yielded clinical benefits by monitoring subsequent glycaemic control.

We showed that the incidence of DM is on an upward trajectory in KZN. Much more emphasis needs to be placed on diabetes control in the context of the COVID-19 pandemic. PLWD with suboptimal control are at increased risk of developing severe COVID-19, with increased mortality rates. ${ }^{[10-12]}$ These findings of a more severe disease and increased mortality resulting from COVID-19 in PLWD with poor glycaemic control do not bode well for the majority of these patients in KZN, who were

\section{Study limitations}

The data were collected during the COVID-19 pandemic and lockdown period, which would have affected the number of diabetes clinic visits.

\section{Conclusions}

Improved glycaemic control has been shown to decrease diabetes-related complications. Our study has demonstrated that the majority of PLWD who visit public healthcare facilities in KZN have suboptimal glycaemic control, indicating that they are at increased risk of shown to have uncontrolled DM. developing diabetes-related complications, further burdening the healthcare fiscus of LMIC. We have also shown that the number of HbAlc tests performed in the face of suboptimal control was well below par, and strategies need to be implemented to increase awareness around the use of $\mathrm{HbAlc}$ testing for monitoring PLWD, and to make point-of-care HbAlc testing more readily available in these healthcare facilities.

\section{Declaration. None.}

\section{Acknowledgements. None.}

Author contributions. The principal author, SP, made substantial contributions to the conception and design of the work, writing of the article and final approval, and agrees to be accountable for all aspects of the research. The co-authors, DP and RP, made substantial contributions to the conception of the work, critically reviewing and editing the draft paper, gave final approval and agreed to be accountable for all aspects of the research.

Funding. None.

Conflicts of interest. None.

1. International Diabetes Federation. About diabetes. https://www.idf org/aboutdiabetes/what-is-diabetes/facts-figures.html\# (accessed org/aboutdiabetes/what-is-diabetes/facts-figures.html\# (accessed 24 May 202

2. International Diabetes Federation. IDF Africa Members. https:// idf.org/our-network/regions-members/africa/members/25-southafrica.html (accessed 24 May 2021)

3. Pillay S, Pillay D, Singh D, Pillay R. Diabetes-related amputations in the public healthcare sector in KwaZulu-Natal: A five-year perspective. Are we winning? JEMDSA 2019;24(1):32-36. https:// doi.org/10.1080/16089677.2018.1550956

4. Amod A, Riback W. Diabetes guidelines and clinical practice: Is there a gap? The South African cohort of the International Diabetes Management Practices Study. JEMDSA 2012;17(2):85-90. https:// doi.org/10.1080.22201009.2012.10872282

5. Pillay S, Aldous C, Mahomed F. Diabetic patients served at a regional level hospital: What is their clinical picture? JEMDSA 2015;20(1):60-66. https://doi.org/10.1080/16089677.2015.1030856 6. Amod A. The 2017 SEMDSA guidelines for the management of 6. Amod A. The 2017 SEMDSA guidelines for the manag
type 2 diabetes. JEMDSA 2017;22(1)(Suppl 1):S1-S196.

7. American Diabetes Association. Implications of the United Kingdom Prospective Diabetes Study. Diabetes Care 2002;25(1):S28-S32. https://doi.org/10.2337/diacare.25.2007.S28

8. Aung WP, Htet AS, Bjertness E, et al. Urban-rural differences in the prevalence of diabetes mellitus among 25 - 74 -year-old adults of the Yangon Region, Myanmar: Two cross-sectional studies. BMJ Open 2018;8(3):e020406. https://doi.org/10.1136/bmjopen-2017-020406 9. Sherwani SI, Khan HA, Ekhzaimy A, Masood A, Sakharkar MK Significance of $\mathrm{HbAlc}$ test in diagnosis and prognosis of diabetic patients. Biomark Insights 2016;11:95-104. https://doi.org/10.4137 BMI.S38440

10. Wang D, Hu B, Hu C, et al. Clinical characteristics of 138 hospitalised patients with 2019 novel coronavirus-infected pneumonia in Wuhan, China. JAMA 2020;323(11):1061-1069. pneumonia in Wuhan, China. JAMA
https://doi.org/10.1001/jama.2020.1585

11. Xiaochen L, Shuyun X, Muqing Y, et al. Risk factors for severity and mortality in adult COVID-19 inpatients in Wuhan. J Allergy Clin Immunol 2020;146(1):110-118. https://doi.org/10.1016/j.
and mortality in adult COVID-19 inpatients in Whan. jaci.2020.04.006

12. Huang C, Wang Y, Li X, et al. Clinical features of patients infected with 2019 novel coronavirus in Wuhan, China. Lance 2020;395(10223):497-506. https://doi.org/10.1016/S01406736(20)30183-5

Accepted 19 July 2021. 